\title{
TENDÊNCIAS TECNOLÓGICAS NA ÁREA DE CIÊNCIAS NATURAIS DO ENSINO MÉDIO: UMA ANÁLISE A PARTIR DOS PCN+ E DA BNCC
}

\section{TECHNOLOGICAL TRENDS IN HIGH SCHOOL NATURAL SCIENCES: AN ANALYSIS FROM PCN+ AND BNCC}

\author{
William Rossani dos Santos ${ }^{1}$
}

\begin{abstract}
Resumo: Esta pesquisa tem como objetivo investigar as tendências tecnológicas presentes no interior de duas propostas curriculares nacionais do ensino médio: as Orientações Educacionais Complementares aos Parâmetros Curriculares Nacionais do Ensino Médio (PCN+) e a Base Nacional Comum Curricular (BNCC). Para atingir tal fim, foi feita a utilização das técnicas de Análise de Conteúdo de Bardin, que contou com duas etapas: a primeira etapa visando a enumeração das frequências dos termos ligados ao radical tecno (tecnologia e tecnológico) em ambos os documentos; e a segunda, almejando a categorização das tendências encontradas a partir da análise de suas respectivas unidades de contexto. Os resultados demonstram uma quantidade de 147 unidades de contextos nos PCN+ em comparação com 30 da BNCC. Dentre as unidades de contexto, seis tendências tecnológicas foram identificadas nos PCN+ enquanto na BNCC apenas cinco destas. Ainda assim, é possível considerá-las como tendências essenciais no processo de Alfabetização Científico-Tecnológica.
\end{abstract}

Palavras-chave: Tendências tecnológicas; Alfabetização Científico-Tecnológica; Ciências Naturais.

\begin{abstract}
This research aims to investigate the technological trends present within two national curricular proposals of high school: the Educational Guidelines Complementary to the National Curriculum Parameters of High School (PCN +) and the Common National Curricular Base (BNCC). To achieve this end, Bardin's Content Analysis techniques were used, which included two stages: the first stage aimed at enumerating the frequencies of terms linked to the radical techno (technology and technology) in both documents; and the second, aiming at categorizing the trends found from the analysis of their respective context units. The results demonstrate an amount of 147 context units in the PCN + compared to 30 in the BNCC. Among the context units, six technological trends were identified in PCN + while in BNCC only five of these. Even so, it is possible to consider them as essential trends in the Scientific-Technological Literacy process.
\end{abstract}

Keywords: Technological trends; Scientific-Technological Literacy; Natural Sciences.

\section{Introdução}

Desde a década de 1970, a educação científica tem se voltado para a problematização das habilidades e competências necessárias ao novo contexto tecnocientífico-informacional, além de ter passado a reconhecer as implicações sociais da Ciência e da Tecnologia nos problemas socioambientais, nas crises econômicas e na disrupção tecnológica (KRASILCHIK, 1992, 2000). A esse respeito, Krasilchik (2000) salienta que a admissão das conexões entre a Ciência e a Sociedade teve implicações na atenuação do foco dado aos aspectos internos à investigação científica e no fortalecimento

\footnotetext{
${ }^{1}$ Mestrando em Ensino e História de Ciências da Terra (UNICAMP). Graduado em Pedagogia (UFSCAR). São Carlos, São Paulo, Brasil. E-mail: william_rossani@hotmail.com
} 
da correlação destes com aspectos políticos, econômicos e culturais (KRASILCHIK, 2000).

Essa nova configuração no campo da educação em ciências, apontada pela autora, deveu-se a uma reanálise de aspectos externos ao ensino que vinham sendo reivindicados nas décadas anteriores, como a necessidade de formação de pequenos cientistas fundamentada na preocupação do progresso social e econômico baseado na Ciência; bem como na reavaliação crítica das perspectivas e metodologias possíveis de serem adotadas ao se ensinar ciências, que envolviam controvérsias como: ensino teórico ou prático; Ciência como produto ou processo; mitificação da Ciência ou Ciência como atividade humana; valorização ou desconsideração do cotidiano do aluno; prevalência da lógica da Ciência ou do aluno; multi ou interdisciplinaridade curricular; função ativa ou passiva do professor; abordagem ecológica ou ambiental; padronização ou flexibilidade do currículo, etc. (AMARAL, 1998).

De acordo com Amaral (1998), as décadas de 1970 e 1980 fizeram emergir objeções ao caráter inquestionável do conhecimento científico e à imagem de objetividade, neutralidade e padronização dos métodos empregados pela Ciência. Para o autor, ficou evidente uma mudança de paradigma do ensino científico a partir da reformulação das concepções acerca da Educação, Ambiente e Ciência instigadas por diferentes movimentos sociais e filosóficos críticos em relação à Ciência Moderna irrompidos neste período. Essa mudança paradigmática na educação passou a considerar características como:

(...) flexibilidade curricular; interdisciplinaridade; desenvolvimento de uma visão sistêmica de ambiente; conscientização da necessidade de preservação da natureza e do uso racional dos recursos naturais; formação de uma imagem da ciência como atividade humana historicamente determinada; articulação entre o senso comum e o conhecimento científico; respeito ao conhecimento prévio e às estruturas cognitivas do estudante; correlação entre psicogênese e história da ciência; incorporação do cotidiano ao processo de ensinoaprendizagem; construção do conhecimento pelo aluno (AMARAL, 1998, p. 220).

Levando em consideração essa nova perspectiva mais atenta às questões de caráter sociocultural da educação científica, autores como Auler e Delizoicov (2001), tem destacado o papel da Alfabetização Científico-Tecnológica como forma de cumprir as metas ligadas ao desenvolvimento de competências necessárias à Sociedade da Informação, alertando, no entanto, para a amplitude desse processo e a necessidade de uma abordagem crítica e problematizadora do conhecimento científico e tecnológico nas salas de aula, precisamente por conta do cuidado com as deformações geradas por uma 
abordagem ingênua da Ciência e da Tecnologia e a desconsideração de suas relações com a sociedade e o meio-ambiente.

De acordo com Auler (2003), a Alfabetização Científico-Tecnológica deve estar associada ao "ensino de conceitos associado à problematização de construções historicamente realizadas sobre a atividade científico-tecnológica, potencializando, assim, uma compreensão crítica sobre interações entre Ciência-Tecnologia-Sociedade" (AULER, 2003, p. 75). Além disso, salienta que seus preceitos devem superar concepções tecnocráticas, salvacionistas e deterministas. Cachapuz (1999), neste mesmo sentido, indica que a aprendizagem deve partir de "situações-problemas", de preferência relativas a contextos reais.

Além de concordar com tais autores, entendemos que, para que seja possível avaliar a forma pela qual os conteúdos voltados à formação científica e tecnológica têm sido veiculados no contexto de ensino, se faz necessário examinar, não só o modo pedagógico de trabalho com tais temáticas, mas, igualmente, as próprias diretrizes curriculares que foram e continuam sendo fundamentais na proposição dessas questões. Pensando nesta perspectiva curricular, objetivamos, com a presente investigação, analisar como as propostas curriculares nacionais têm tratado os conteúdos necessários ao desenvolvimento da Alfabetização Científico-Tecnológica dos estudantes brasileiros, tendo como foco em especial, o fenômeno tecnológico, central ao contexto atual.

A análise aqui empreendida tem como base pesquisa anterior, que traz como evidência, pelo menos, seis tendências tecnológicas presentes nas normativas nacionais do ensino fundamental (Parâmetros Curriculares Nacionais e na Base Nacional Comum Curricular), a saber: Aspectos Cognoscitivos; Associação entre Tecnologia e Ciência; Desenvolvimento e aplicação dos aparatos tecnológicos; Enfoque CTS; História da Ciência e da Tecnologia; e Relação entre Natureza e Tecnologia (SANTOS, 2021, no prelo). Essas tendências pressupõem diferentes enfoques empregados no tratamento do curricular do fenômeno tecnológico, principalmente ligados aos âmbitos cognitivo, histórico, social, cultural, utilitário, associativo e ambiental.

Dada essa vasta gama de enfoques possíveis na abordagem tecnológica, a nova questão que buscamos responder é a seguinte: as tendências encontradas nas etapas iniciais e finais do Ensino Fundamental também são evidenciadas nos três anos do ensino médio destas mesmas propostas curriculares? Acreditamos que a resposta para essa questão é fundamental para a discussão da continuidade e da consistência de certos tópicos na educação científica dos estudantes brasileiros, bem como para refletir se tais 
tendências refletem as preocupações atuais acerca do contexto contemporâneo, centradas na relação entre Ciência, Tecnologia e Sociedade.

Tal como a investigação anterior, o objetivo específico deste trabalho foi o de identificar a frequência de aparecimento das terminologias referentes à Tecnologia e as suas respectivas tendências. No entanto, também buscamos analisar as implicações acríticas e críticas de tais tendências de acordo com as categorias de Perspectiva Reducionista e Perspectiva Ampliada, adotadas por Auler e Delizoicov (2001).

De acordo com estes autores, a Perspectiva Reducionista refere-se a uma "postura pouco crítica em relação às implicações da Ciência e da Tecnologia na sociedade" (AULER; DELIZOICOV, 2001, p. 128), que tem por fundamento três princípios básicos:

a) O público é ignorante sobre questões científicas e tecnológicas. As controvérsias públicas sobre questões científicas e técnicas são atribuídas a um entendimento inadequado, por parte do público, e não devido ao funcionamento da ciência em si;

b) A visão de mundo oferecida pela ciência é considerada única e privilegiada, constituindo um fator essencial para a melhoria das condições humanas e ambientais;

c) A ciência é retratada como uma atividade neutra, desprovida de valores. As condições sob as quais o conhecimento científico é construído e validado não são questionadas e à ciência é atribuído um caráter de atividade desprovida de ambiguidades e contradições (AULER; DELIZOICOV, 2001, p. 128).

Em contraposição, a Perspectiva Ampliada sugere a superação de uma percepção ingênua e mágica da realidade que "exige, cada vez mais, uma compreensão dos sutis e delicados processos de interação entre CTS. Exige um 'desvelamento' dos discursos ideológicos vinculados à CT, manifestos, muitas vezes, na defesa da entrega do destino, da sociedade, à tecnocracia" (AULER; DELIZOICOV, 2001, p. 129), além de se aproximar de alguns aspectos basilares da pedagogia freiriana, que considera o diálogo e a problematização como eixos centrais de uma educação crítica.

A escolha de categorias de análise como estas foi feita tendo em vista o fato de que tornam possíveis, não só identificar, mas também entender as concepções que parametrizam as tendências tecnológicas veiculadas no currículo adotado pelo professor em seu processo de ensino, o que é essencial, tanto para avaliar o nível de criticidade que estes conteúdos abrangem, como para orientar ações de êxito no processo de ensino e aprendizagem da Ciência e da Tecnologia no âmbito da educação. 


\section{Procedimento Metodológico}

O estudo caracteriza-se como uma pesquisa qualitativa e adota as técnicas da Análise de Conteúdo de Bardin (2002), que se desenvolve a partir de três etapas distintas: Pré-análise; Exploração do Material; e Tratamento dos Resultados.

De acordo com Bardin (2002), a primeira etapa consiste na seleção dos materiais utilizados de acordo com os objetivos definidos, ou inversamente. Baseado nos objetivos de identificar a frequência e as tendências do enfoque tecnológico nas diretrizes curriculares nacionais do ensino médio, fizemos uso de duas grandes normativas, a saber: As Orientações Educacionais Complementares aos Parâmetros Curriculares Nacionais para o Ensino Médio (PCN+) e a Base Nacional Comum Curricular do Ensino Médio (BNCC). A escolha de ambos os documentos se deu por suas estruturas semelhantes, ancoradas em competências e habilidades. Ademais, essa escolha se adequa às regras necessárias à seleção criteriosa do corpus documental indicada por Bardin (2002): 1. ao integrar uma amostragem que pudesse contemplar, pelo menos, duas grandes propostas curriculares nacionais do ensino médio, que continuam servindo de diretrizes curriculares para os professores em seus contextos de trabalho, no caso: ambos os documentos supracitados (Regra da representatividade); 2. ao obedecer aos critérios de homogeneidade na seleção dos materiais, na medida em que são grandes orientações curriculares nacionais da educação básica, voltadas para a disciplina de Ciências da Natureza e estarem situadas em uma única etapa de ensino: ensino médio (Regra da homogeneidade); 3. ao se adequar aos objetivos e conteúdos a serem analisados (Regra da Pertinência); 4. e ao serem documentos passíveis de esgotamento de todo o assunto a ser analisado sem omissão de nenhuma parte, pela leitura e codificação integral de cada um deles (Regra de exaustividade).

A exploração do material contou com duas etapas: uma primeira etapa dedicada à verificação da frequência das terminologias referentes ao radical tecno na área de Ciências Naturais (conteúdos manifestos com base no nível linguístico e semântico) em ambos os documentos, buscando a identificação, principalmente, dos termos tecnologia e tecnológico; e uma segunda etapa visando a categorização de tendências baseadas na análise dos núcleos contextuais identificados na etapa precedente.

A categorização das tendências nesta etapa de ensino (ensino médio) teve como respaldo as seis tendências já localizadas em pesquisa anterior a partir da análise dos Parâmetros Curriculares Nacionais (PCN) e da Base Nacional Comum Curricular 
(BNCC) na etapa fundamental de ensino: 1. Desenvolvimento e aplicação dos aparatos tecnológicos; 2. Relação entre Natureza e Tecnologia; 3. Perspectiva CTS; 4. História da Ciência e da Tecnologia; 5. Aspectos Cognoscitivos; e 6. Associação entre Tecnologia e Ciência (SANTOS, 2021, no prelo).

Por fim, os resultados foram organizados em tabelas (Tabela 1) e quadros (Quadro 1 e Quadro 2) para a posterior discussão dos dados. Cada uma das tendências foi discutida à luz de duas perspectivas ligadas ao desenvolvimento da Alfabetização CientíficoTecnológica propostas por Auler e Delizoicov (2001), quais sejam: Perspectiva Reducionista, tida como uma visão ingênua da Ciência e da Tecnologia, e Perspectiva Ampliada, que considera a Ciência e a Tecnologia como meios para a compreensão dos temas socialmente relevantes.

\section{Frequência das terminologias "Tecnologia" e "Tecnológico" no interior dos documentos analisados}

Bardin (2002) esclarece que uma das três etapas fundamentais da organização da codificação é o processo de enumeração. A enumeração consiste nas regras e nos modos de contagem, de acordo com o recorte de análise. Ademais, a enumeração por frequência permite a contagem das ocorrências dos termos em determinado documento que indicará as unidades de contexto necessárias de serem analisadas, isto é, os recortes terminológicos definidos pelo pesquisador. Pensando nas tendências com enfoque tecnológico pretendidas de serem identificadas, optamos pela obtenção de frequências de aparições de todos os termos relativos ao radical tecno, principalmente aqueles relativos às terminologias tecnologia e tecnológico.

A Tabela 1 indica os resultados quantitativos obtidos pela exploração da área de Ciências Naturais das duas normativas selecionadas ${ }^{2}$. Os $\mathrm{PCN}+$ evidenciam uma frequência de 185 termos, sendo 38 deles referentes às unidades de significado, isto é, termos sem qualquer sentido estrito em relação a frase, período ou parágrafo, localizados nos títulos de tópicos e quadros (BRASIL, 2002, p. 32, 36, 37, 39, 40, 47, 63, 64, 67, 68, 74, 89, 90, 92, 93); no interior do referencial teórico, geralmente sob a frase "área de Ciências da Natureza, Matemática e suas Tecnologias" (BRASIL, 2002, p. 4, 7, 21, 23, $32,88,113,134)$; e sob a forma de termos isolados, tais como "Secretaria de Ensino

\footnotetext{
${ }^{2}$ Embora a disciplina Matemática esteja incluída nos $\mathrm{PCN}+$, esta não foi considerada na contagem terminológica.
} 
Médio e Tecnológico" (BRASIL, 2002, p. 142, grifo nosso). Já em relação à frequência das unidades de contexto, este documento quantifica 147 termos, que podem ser verificados no Quadro 1.

Pela análise da área de Ciências da Natureza e suas Tecnologias da BNCC, verificamos um total de 37 termos, entre 7 unidades de significado, localizadas nos títulos dos tópicos e nos comentários da área, em específico, na frase "Ciências da Natureza e suas Tecnologias" (BRASIL, 2018, p. 537, 538, 539, 540); e 30 unidades de contexto, localizados no decorrer de todo o texto, principalmente no referencial teórico da área, nas Competências Específicas e nas Habilidades do ensino médio, agregando os termos tecnologia(s), (processos/sistemas/avanços/temas) tecnológicos, (desenvolvimento/ conhecimento) tecnológico, (aplicações) tecnológicas - mais detalhados no Quadro 2.

Tabela 1: Frequência de Aparição das Terminologias Tecno

\begin{tabular}{ccc}
\hline DOCUMENTOS & PCN+ (2002) & BNCC (2018) \\
\hline Unidade de significado & 38 & 7 \\
\hline Unidade de contexto & 147 & 30 \\
\hline Total & 185 & 37 \\
\hline
\end{tabular}

Fonte: autor, com base em Brasil (2002, 2018).

A frequência das unidades de contexto dos $\mathrm{PCN}+\mathrm{e}$ da $\mathrm{BNCC}$, como indicados na Tabela 1, serviram de orientação para a identificação e classificação de tendências tecnológicas, que serão delineadas a seguir.

\section{Tendências Tecnológicas na área de Ciências Naturais}

Bardin (2002) esclarece que a realização de uma análise contextual permite a localização dos 'núcleos de sentido' que compõem a comunicação. De acordo com a autora, a presença ou frequência de aparição desses núcleos de sentido podem significar alguma coisa para o objetivo analítico escolhido. A autora ainda destaca que "o tema é geralmente utilizado como unidade de análise para estudar motivações de opiniões, de atitudes, de valores, de crenças, de tendências, etc" (BARDIN, 2002, p. 106, grifo nosso). Dada a possibilidade de localização de questões temáticas referentes ao enfoque tecnológico, recorremos à codificação dos núcleos do sentido em busca de certas 
tendências que pudessem elucidar um padrão no tratamento tecnológico nas propostas curriculares nacionais.

De modo a encontrar uma definição satisfatória em termos conceituais e metodológicos, consideramos como tendências tecnológicas as categorias que nos permitiram encontrar certos padrões contextuais e temáticos semelhantes e que se apresentaram de forma predominante em cada um dos documentos. Tais tendências estiveram relacionadas à ampla gama de abordagens tratadas de modo constante nesses materiais e marcadas por palavras-chaves específicas, como podem ser visualizadas no Quadro 1 e no Quadro 2. As abordagens predominantes encontradas referem-se, no geral, à compreensão dos conhecimentos tecnocientíficos, aos aspectos históricos, sociais e éticos, aos elementos naturais e à associação entre diferentes domínios, como é caso da complexa relação entre Ciência e Tecnologia. Como será mencionado adiante, em algumas ocasiões, foi feita a análise de trechos semelhantes para a categorização de tendências divergentes, na medida em que muitos deles possuíam mais de um núcleo de sentido.

\subsection{Tendências Tecnológicas na área de Ciências Naturais das Orientações}

\section{Educacionais Complementares aos Parâmetros Curriculares Nacionais do Ensino} Médio

O Quadro 1 apresenta as tendências categorizadas com a coleta das unidades de contextos dos $\mathrm{PCN}+$, considerando todos os tópicos e subtópicos do documento, entre eles a fundamentação teórica (A reformulação do ensino médio e as áreas do conhecimento e As Ciências da Natureza e a Matemática), as áreas específicas das Ciências Naturais (Biologia, Física, Química), além dos tópicos intitulados $O$ ensino articulado das ciências e sua avaliação e Formação profissional permanente dos professores. As unidades de contexto foram compiladas por meio de termos isolados e fragmentos com sentido, baseados no radical tecno:

Quadro 1: Categorização das Tendências Tecnológicas nos PCN+

\begin{tabular}{|c|l|}
\hline $\begin{array}{c}\text { Tendências } \\
\text { Tecnológicas }\end{array}$ & \multicolumn{1}{|c|}{ Unidades de contexto } \\
\hline & $\begin{array}{l}\text { "[...] compreender processos, sejam eles sociais, naturais, culturais ou } \\
\text { tecnológicos." (p.15; 16); "Analisar a transcrição de um problema [...] } \\
\text { tecnológico." (p.17); "Consultar, analisar e interpretar textos e comunicações de } \\
\text { ciência e tecnologia veiculados por diferentes meios." (p.27; 36-37; 63-64; 89; }\end{array}$ \\
$\begin{array}{l}\text { Aspectos } \\
\text { Cognoscitivos } \\
\text { ciência e tecnologia." (p.27; 37; 64; } 90 ; 115) ; \text { "Reconhecer, utilizar, interpretar }\end{array}$ \\
\hline
\end{tabular}




\begin{tabular}{|c|c|}
\hline & 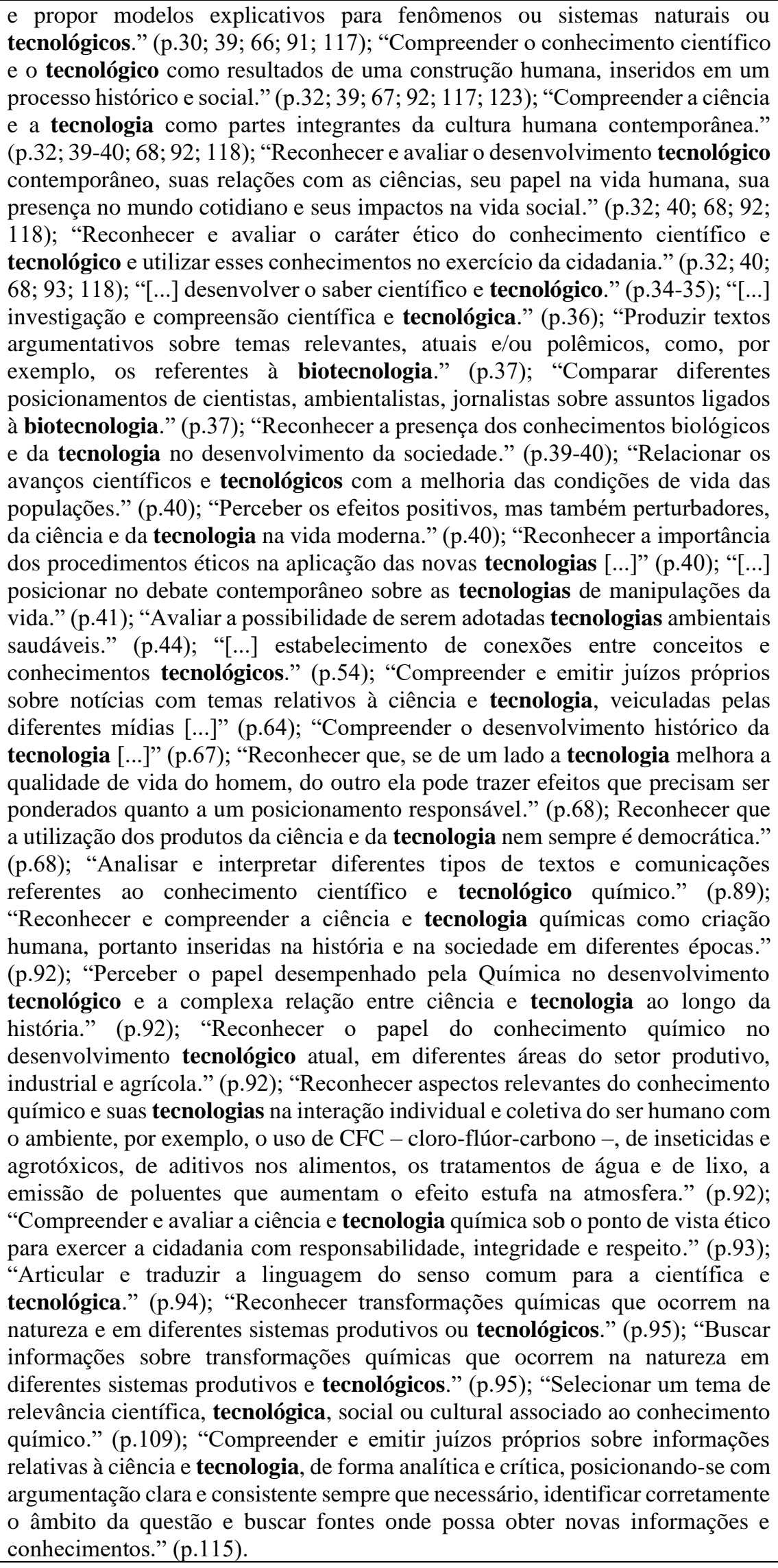 \\
\hline $\begin{array}{l}\text { Associação entre } \\
\text { Tecnologia e } \\
\text { Ciência }\end{array}$ & 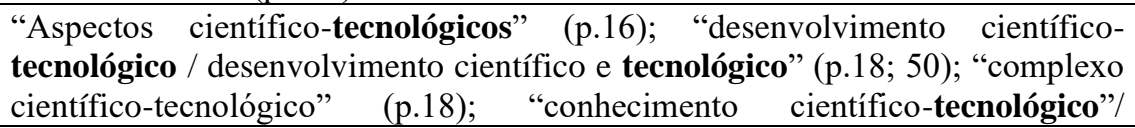 \\
\hline
\end{tabular}




\begin{tabular}{|c|c|}
\hline & 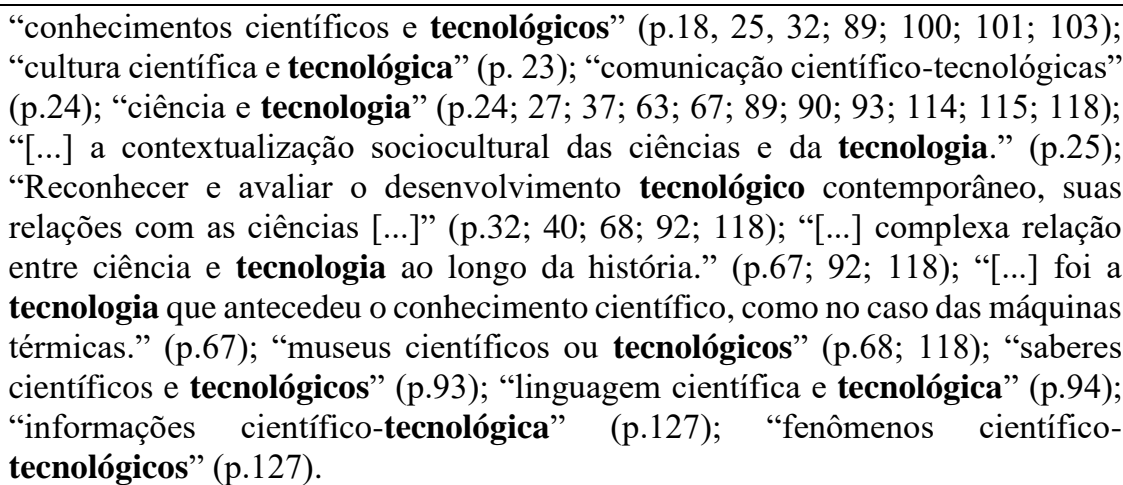 \\
\hline $\begin{array}{l}\text { Desenvolvimento e } \\
\text { aplicação de } \\
\text { aparatos } \\
\text { tecnológicos }\end{array}$ & 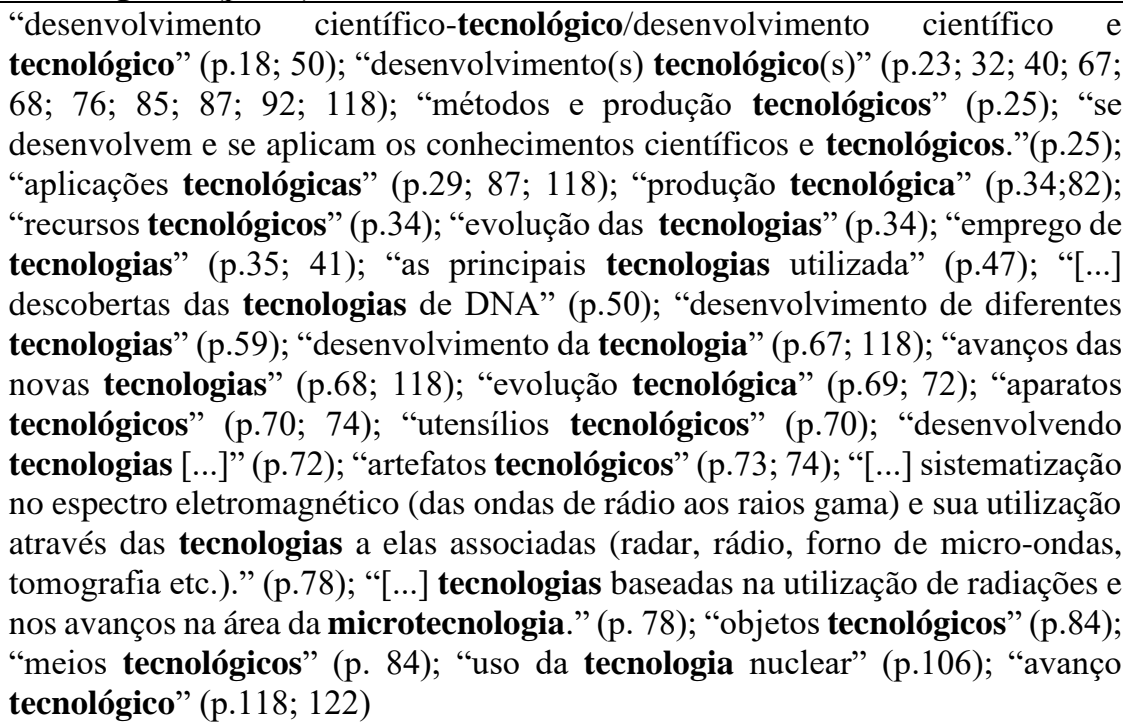 \\
\hline Enfoque CTS & 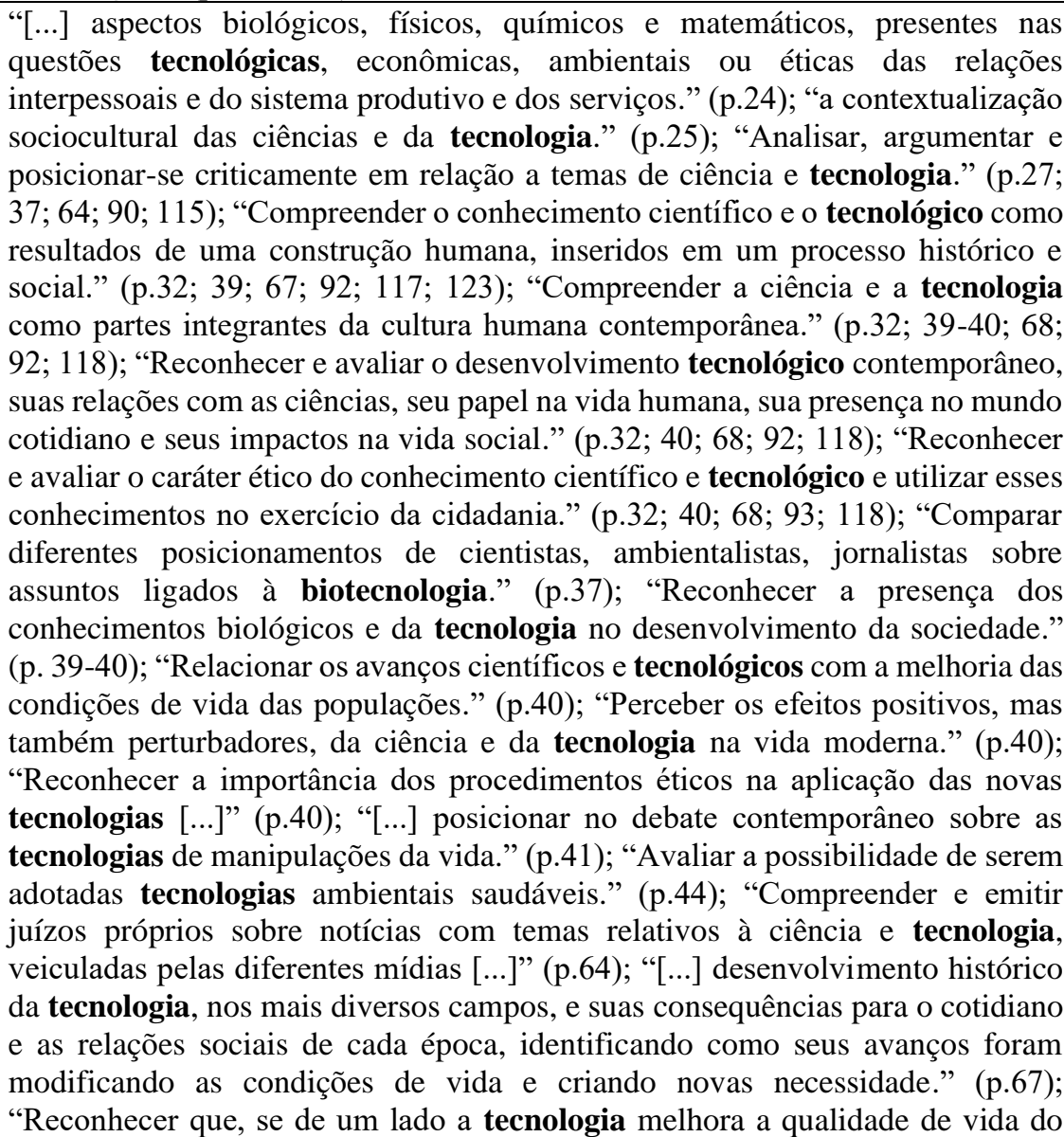 \\
\hline
\end{tabular}




\begin{tabular}{|c|c|}
\hline & $\begin{array}{l}\text { homem, do outro ela pode trazer efeitos que precisam ser ponderados quanto a } \\
\text { um posicionamento responsável." (p.68); "Reconhecer que a utilização dos } \\
\text { produtos da ciência e da tecnologia nem sempre é democrática." (p.68); "[...] } \\
\text { implicações sociais e tecnológicas." (p.73); "[...] relacionando-os ao } \\
\text { desenvolvimento econômico, tecnológico e à qualidade de vida ao longo do } \\
\text { tempo." (p.74); "[...] impacto da tecnologia nas formas de vida } \\
\text { contemporâneas." (p.77); "[...] aplicações tecnológicas e suas implicações } \\
\text { ambientais, sociais, políticas e econômicas." (p.87); "Reconhecer e compreender } \\
\text { a ciência e tecnologia químicas como criação humana, portanto inseridas na } \\
\text { história e na sociedade em diferentes épocas." (p.92); "Perceber o papel } \\
\text { desempenhado pela Química no desenvolvimento tecnológico e a complexa } \\
\text { relação entre ciência e tecnologia ao longo da história." (p.92); "Reconhecer o } \\
\text { papel do conhecimento químico no desenvolvimento tecnológico atual, em } \\
\text { diferentes áreas do setor produtivo, industrial e agrícola." (p.92); "Reconhecer } \\
\text { aspectos relevantes do conhecimento químico e suas tecnologias na interação } \\
\text { individual e coletiva do ser humano com o ambiente, por exemplo, o uso de CFC } \\
\text { - cloro-flúor-carbono -, de inseticidas e agrotóxicos, de aditivos nos alimentos, } \\
\text { os tratamentos de água e de lixo, a emissão de poluentes que aumentam o efeito } \\
\text { estufa na atmosfera." (p.92); "Compreender e avaliar a ciência e tecnologia } \\
\text { química sob o ponto de vista ético para exercer a cidadania com responsabilidade, } \\
\text { integridade e respeito." (p.93); "[...] como os saberes científico e tecnológico } \\
\text { vêm interferindo na produção, na cultura e no ambiente." (p.93); "Compreender } \\
\text { e emitir juízos próprios sobre informações relativas à ciência e tecnologia, de } \\
\text { forma analítica e crítica, posicionando-se com argumentação clara e consistente } \\
\text { sempre que necessário, identificar corretamente o âmbito da questão e buscar } \\
\text { fontes onde possa obter novas informações e conhecimentos." (p.115). }\end{array}$ \\
\hline $\begin{array}{l}\text { História da } \\
\text { Ciência e da } \\
\text { Tecnologia }\end{array}$ & 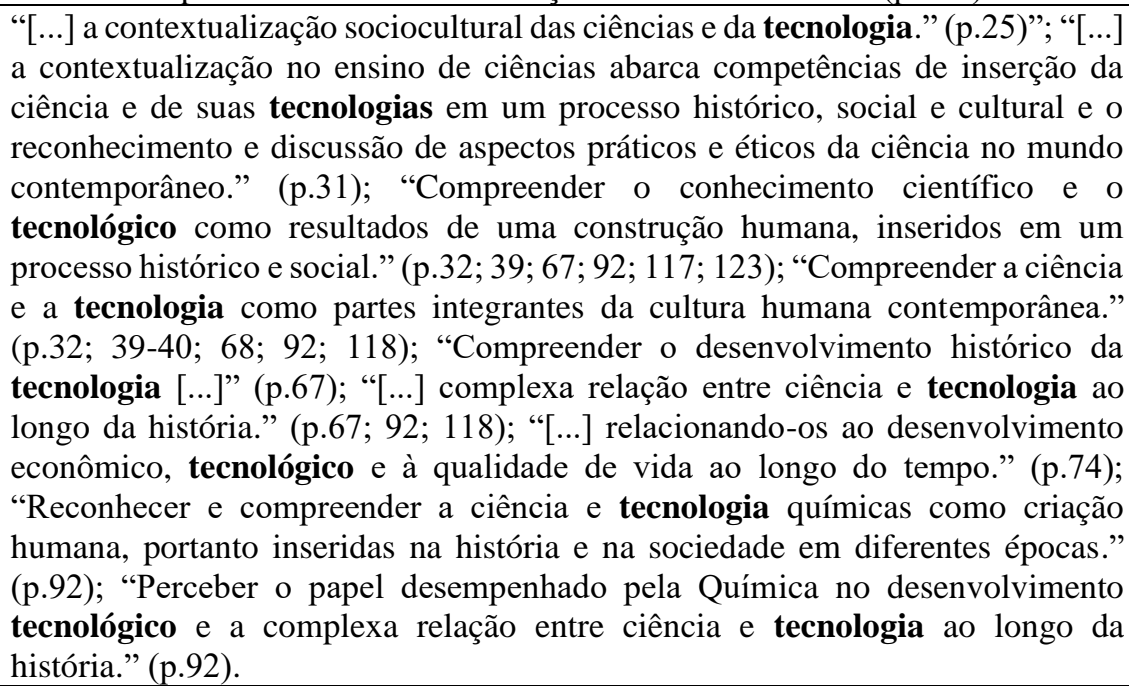 \\
\hline $\begin{array}{c}\text { Relação entre } \\
\text { Natureza e } \\
\text { Tecnologia }\end{array}$ & $\begin{array}{l}\text { "[...] investigação da natureza e dos desenvolvimentos tecnológicos." (p. 23); } \\
\text { "processos naturais e tecnológicos" (p.23; 87; 93); "fenômenos naturais e } \\
\text { tecnológicos/fenômenos naturais e processo tecnológicos" (p.59; 74); "[...] } \\
\text { tratando do ambiente, da vida, da tecnologia, da Terra." (p.69); "sistemas } \\
\text { naturais e tecnológicos" (p. 73; 97); "ambientes naturais e tecnológicos" (p.94) }\end{array}$ \\
\hline Outros & 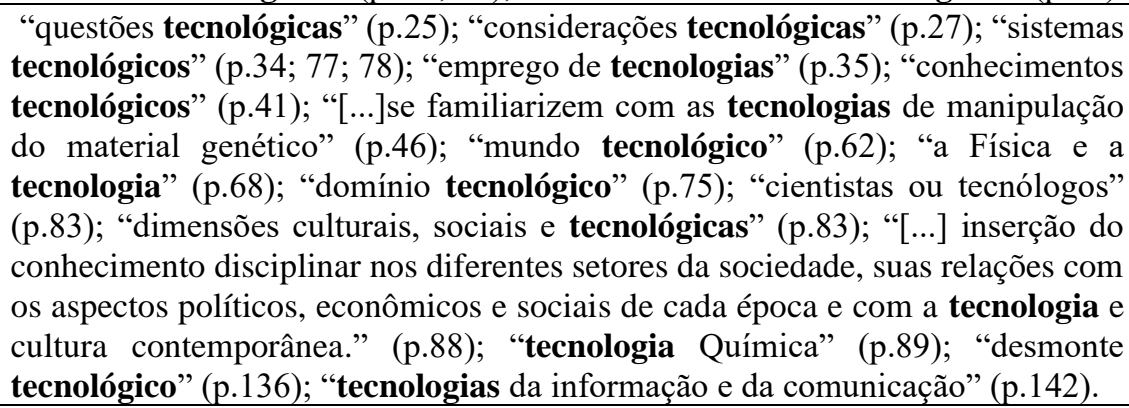 \\
\hline
\end{tabular}

Fonte: autor, com base em BRASIL (2002). 
A codificação das tendências tecnológicas com base na seleção de unidades de contexto presentes nos PCN+ indica, em ordem decrescente, a seguinte ocorrência: um maior número de termos e fragmentos está relacionado à tendência que denominamos Aspectos Cognoscitivos, que consiste na demanda de desenvolvimento de certas competências e habilidades pelos estudantes, caracterizada por verbos de ação. Dentre esses verbos, pode-se pontuar os seguintes: compreender, consultar, analisar, interpretar, argumentar e posicionar-se, reconhecer, avaliar, propor, desenvolver, produzir, comparar, relacionar, perceber, posicionar, estabelecer, articular, buscar, selecionar, conhecer e emitir juízos — todos ligados aos procedimentos e à compreensão do conhecimento tecnocientífico.

Nota-se que, grande parte das unidades de contexto em que esses verbos foram localizados estão inseridas no conjunto de competências gerais que permeiam as áreas das Ciências Naturais, as quais demandam metas de aprendizagem específicas, inclusive, no enfoque tecnológico em análise. De acordo com o documento, "As competências gerais, que orientam o aprendizado no ensino médio, devem ser promovidas pelo conjunto das disciplinas dessa área, que é mais do que uma reunião de especialidades" (BRASIL, 2002, p. 24). Em outras palavras, compreende-se que cada competência específica envolve uma multiplicidade de matérias e temáticas que estão organizadas de maneira transversal. Como veremos a seguir, as diferentes tendências tecnológicas seguem este mesmo padrão, ao estarem articuladas entre si.

Ao analisarmos as unidades de contexto dessa primeira tendência verifica-se que estão inseridas nas três grandes competências que o documento dispõe, a saber: 1. Representação e Comunicação, que no enfoque tecnológico, se delineia em duas competências específicas: Análise e interpretação de textos e outras comunicações, que indica a ação de se "Consultar, analisar e interpretar textos e comunicações de ciência e tecnologia veiculados por diferentes meios” (BRASIL, 2002, p. 28) e Discussão e argumentação de temas de interesse, que sugerem aos estudantes "Analisar, argumentar e posicionar-se criticamente em relação a temas de ciência e tecnologia" (BRASIL, 2002, p. 28); 2. Investigação e Compreensão, principalmente em relação aos Modelos explicativos e representativos, sob a competência específica de "Reconhecer, utilizar, interpretar e propor modelos explicativos para fenômenos ou sistemas naturais ou tecnológicos" (BRASIL, 2002, p. 30; 39; 66; 91; 117); e, por fim, a competência ligada à 3. Contextualização Sociocultural da Ciência e da Tecnologia, com quatro competências específicas: Ciência e tecnologia na história, sob o imperativo de se "Compreender o 
conhecimento científico e o tecnológico como resultados de uma construção humana, inseridos em um processo histórico e social"; Ciência e tecnologia na cultura contemporânea, indicando o ato de se "Compreender a ciência e a tecnologia como partes integrantes da cultura humana contemporânea"; Ciência e tecnologia na atualidade, visando "Reconhecer e avaliar o desenvolvimento tecnológico contemporâneo, suas relações com as ciências, seu papel na vida humana, sua presença no mundo cotidiano e seus impactos na vida social" (BRASIL, 2002, p. 32; 40; 68; 92; 118); e Ciência e tecnologia, ética e cidadania, orientando a "Reconhecer e avaliar o caráter ético do conhecimento científico e tecnológico e utilizar esses conhecimentos no exercício da cidadania” (BRASIL, 2002, p.32; 40; 68; 93; 118).

Em linhas gerais, entendemos que a tendência intitulada Aspectos Cognoscitivos está centralmente voltada para o desenvolvimento estrito do que se pode definir como Alfabetização Científico-Tecnológica, isto é, as ações cognitivas e práticas da educação científica e tecnológica, visando a inserção no mundo tecnocientífico. É evidente que esses aspectos cognoscitivos estão articulados com mais de uma tendência, uma vez que as competências específicas descrevem diferentes enfoques (histórico, social, utilitário, associativo, ambiental), como, por exemplo, na competência geral Contextualização Sociocultural, cuja competência específica prescreve ao estudante "Compreender o conhecimento científico e o tecnológico como resultados de uma construção humana, inseridos em um processo histórico e social.” (BRASIL, 2002, p. 32; 39; 67; 92; 117; 123). Nessa passagem, pelo menos mais duas tendências podem ser demarcadas, além da que denominamos Aspectos Cognoscitivos: a tendência História da Ciência e da Tecnologia, que delimita uma abordagem histórico-social e o Enfoque CTS, subentendido a partir das inter-relações entre ação humana, sociedade e produtos.

Com efeito, em segundo lugar no quesito de frequências de aparecimento, encontramos as ocorrências da tendência Enfoque CTS, que considera aspectos sociais e éticos do fazer científico e tecnológico, além de reconhecer as implicações das instituições, sistemas e relações sociais nestes âmbitos, como destacado anteriormente. Suas principais marcas são oriundas dos tópicos de competência específica Ciência e tecnologia na atualidade e Ciência e tecnologia, ética e cidadania e seu enquadramento pôde ser feito a partir de termos como implicações sociais e tecnológicas, o caráter ético do conhecimento tecnológico, e aos trechos representativos do caráter crítico dos indivíduos frente às questões tecnológicas, tal como indicado no Quadro 1. 
Em seguida, foi localizada a tendência Desenvolvimento e Aplicação dos aparatos tecnológicos, correspondente ao desenvolvimento das tecnologias e ao uso dos produtos científicos pelos indivíduos na sociedade. Foi possível notar uma vinculação considerável com as tendências históricas e sociais, por esse processo ser condicionado pela cultura e pelas relações humanas. Nessa tendência também foi considerada a demanda do uso em sala de aula das tecnologias digitais e da comunicação por parte dos estudantes para desenvolvimento de atividades pedagógicas, por exemplo, quando o documento salienta que não se pode "em pleno século 21, abrir mão dos recursos oferecidos pela tecnologia da informação e da comunicação e da capacitação dos professores para a utilização plena desses recursos" (BRASIL, 2002, p. 142). Essa tendência também esteve articulada com substantivos bastante particulares da Tecnologia, como aparatos tecnológicos, recursos tecnológicos, objetos tecnológicos, utensílios tecnológicos, etc., bem como pela constância dos termos produção, desenvolvimento e avanço tecnológicoldas tecnologias.

Em quarto lugar, foi delimitada a tendência Associação entre Ciência $e$ Tecnologia, que coloca ênfase na relação intrínseca entre esses dois domínios quando se utilizam do conectivo de ligação "e" (Ciência $e$ Tecnologia) ou o uso do hífen para demarcar o adjetivo composto (científico-tecnológico) indicando a indissociação entre os aspectos tecnocientíficos. A vinculação com outras tendências também é evidente, por exemplo, no destaque da "complexa relação entre ciência e tecnologia ao longo da história" (BRASIL, 2002, p.67, grifo nosso). Há que se destacar que, por estar presente em todas as competências gerais do documento sob a forma do enunciado Ciência $e$ Tecnologia, é possível inferir que a associação entre ambos os campos são intencionais direta e indiretamente em todo o documento.

Em relação à quinta tendência, História da Ciência e da Tecnologia, grande parte dos fragmentos desta foram apreendidos dos tópicos de competências específicas Ciência e tecnologia na história e Ciência e tecnologia na cultura contemporânea. Dentre os principais focos das unidades de contexto para a definição de tal perspectiva, podemos citar o aparecimento frequente das terminologias história, processo histórico, ao longo da história, ao longo do tempo, além de outras terminologias mais genéricas referentes ao desenvolvimento da cultura e ao conhecimento tecnológico e científico como um constructo humano e social, também dispostas no Quadro 1.

Por fim, consideramos uma última tendência aqui denominada por Relação entre Natureza e Tecnologia, que remete a uma preocupação dos impactos da Tecnologia na natureza, mas também ao entendimento associativo das tecnologias na modificação do 
meio-ambiente. Essa tendência se coaduna profundamente com o Enfoque CTS, por implicar na preocupação, não só das causas, mas dos efeitos dos produtos tecnológicos humanos no meio natural.

Fazendo a comparação dos PCN+ do ensino médio com os PCN dos quatro ciclos do ensino fundamental (BRASIL, 1997, 1998) analisadas em pesquisa anterior (SANTOS, 2021, no prelo), não é possível perceber o acréscimo de outras tendências a não ser as seis supracitadas e dispostas no Quadro 1. Esse limite de tendências nos chamados Parâmetros Curriculares Nacionais pode ser compreendido, pois todos esses documentos correspondem a propostas curriculares com objetivos, conteúdos e competências específicas que os perpassam de forma similar, embora com sua especificidade de acordo com cada um dos ciclos e etapas de ensino. A única diferença identificável pode ser atribuída aos fragmentos inseridos na categoria denominada Outros, por se enquadrarem no interior de determinadas unidades de contexto, mas não corresponderem a nenhum processo padrão, considerado como uma tendência de fato.

\subsection{Tendências Tecnológicas na área de Ciências Naturais da Base Nacional Comum Curricular do Ensino Médio}

Em relação à $\mathrm{BNCC}$, das seis tendências encontradas no documento anterior, pudemos localizar apenas cinco delas na área de Ciências Naturais a partir das 30 unidades de contexto identificadas na etapa 1. Essas cinco tendências podem ser verificadas no Quadro 2:

Quadro 2: Categorização das Tendências Tecnológicas na BNCC do Ensino Médio

\begin{tabular}{|c|c|}
\hline $\begin{array}{l}\text { Tendências } \\
\text { Tecnológicas }\end{array}$ & Unidades de Contexto \\
\hline $\begin{array}{c}\text { Aspectos } \\
\text { Cognoscitivos }\end{array}$ & $\begin{array}{l}\text { "[...] focalizar a interpretação de fenômenos naturais e processos tecnológicos de } \\
\text { modo a possibilitar aos estudantes a apropriação de conceitos, procedimentos e } \\
\text { teorias dos diversos campos das Ciências da Natureza." (p. 537); "A BNCC propõe } \\
\text { que os estudantes aprofundem e ampliem suas reflexões a respeito das tecnologias, } \\
\text { tanto no que concerne aos seus meios de produção e seu papel na sociedade atual } \\
\text { como também em relação às perspectivas futuras de desenvolvimento tecnológico. } \\
\text { Desse modo, propõe continuidade ao tratamento dado no Ensino Fundamental, } \\
\text { etapa na qual as tecnologias foram abordadas sob uma perspectiva de aplicação de } \\
\text { conhecimentos e análise de seus efeitos sobre a saúde e a qualidade de vida das } \\
\text { pessoas." (p.538); "Analisar fenômenos naturais e processos tecnológicos. } \\
\text { (p.539;540); "Os fenômenos naturais e os processos tecnológicos são analisados } \\
\text { sob a perspectiva das relações entre matéria e energia." (p.540); "Realizar } \\
\text { previsões, avaliar intervenções [...] com base na [...] composição dos sistemas } \\
\text { naturais e tecnológicos." (p.541); "Avaliar tecnologias e possíveis soluções para } \\
\text { as demandas que envolvem a geração, o transporte, a distribuição e o consumo de } \\
\text { energia elétrica." (p.541); "Utilizar noções de probabilidade e incerteza para } \\
\text { interpretar previsões sobre atividades experimentais, fenômenos naturais e } \\
\text { processos tecnológicos, reconhecendo os limites explicativos das ciências." }\end{array}$ \\
\hline
\end{tabular}




\begin{tabular}{|c|c|}
\hline & $\begin{array}{l}\text { (p.543); "Analisar situações-problema e avaliar aplicações do conhecimento } \\
\text { científico e tecnológico e suas implicações no mundo, utilizando procedimentos e } \\
\text { linguagens próprios das Ciências da Natureza, para propor soluções que } \\
\text { considerem demandas locais, regionais e/ou globais, e comunicar suas descobertas } \\
\text { e conclusões a públicos variados, em diversos contextos e por meio de diferentes } \\
\text { mídias e tecnologias digitais de informação e comunicação (TDIC)." (p.544); } \\
\text { "Avaliar as aplicações do conhecimento científico e tecnológico nas diversas } \\
\text { esferas da vida humana com ética e responsabilidade." (p.544); "Discussões sobre } \\
\text { as tecnologias relacionadas à geração de energia elétrica" (p.544); "[...] explorar } \\
\text { como os avanços científicos e tecnológicos [...] (p.544)"; "Analisar e debater } \\
\text { situações controversas sobre a aplicação de conhecimentos da área de Ciências da } \\
\text { Natureza (tais como tecnologias do DNA." (p.545); "Compreender as tecnologias } \\
\text { contemporâneas e avaliar seus impactos." (p.545); "[...] discutir a necessidade de } \\
\text { introdução de alternativas e novas tecnologias energéticas e de materiais." (p.545); } \\
\text { "Analisar as propriedades específicas dos materiais para avaliar a adequação de seu } \\
\text { uso em diferentes aplicações (industriais, cotidianas, arquitetônicas ou } \\
\text { tecnológicas) e/ou propor soluções seguras e sustentáveis." (p.545). }\end{array}$ \\
\hline $\begin{array}{c}\text { Associação entre } \\
\text { Ciência e } \\
\text { Tecnologia }\end{array}$ & $\begin{array}{l}\text { "avanços científicos e tecnológicos" (p.544); "conhecimento científico e } \\
\text { tecnológico (p.539; 544); "temas científicos e/ou tecnológicos" (p.545); “. }\end{array}$ \\
\hline $\begin{array}{l}\text { Desenvolvimento } \\
\text { e aplicação de } \\
\text { aparatos } \\
\text { tecnológicos }\end{array}$ & 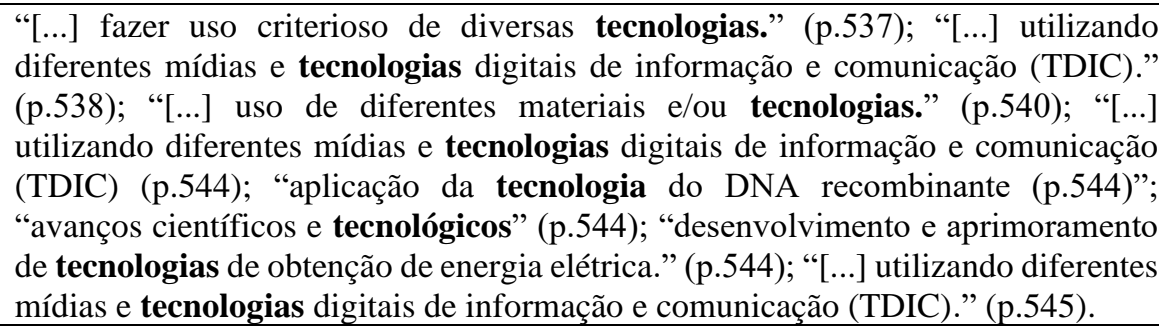 \\
\hline Enfoque CTS & $\begin{array}{l}\text { "A BNCC propõe que os estudantes aprofundem e ampliem suas reflexões a } \\
\text { respeito das tecnologias, tanto no que concerne aos seus meios de produção e seu } \\
\text { papel na sociedade atual como também em relação às perspectivas futuras de } \\
\text { desenvolvimento tecnológico." (p.538); "[...] impactos da tecnologia nas relações } \\
\text { humanas e suas implicações éticas, morais, políticas e econômicas, e sobre seus } \\
\text { riscos e benefícios para a humanidade e o planeta." (p. 544); "analisar situações- } \\
\text { problema e avaliar as aplicações do conhecimento científico e tecnológico nas } \\
\text { diversas esferas da vida humana com ética e responsabilidade" (p.544); } \\
\text { "Compreender as tecnologias contemporâneas e avaliar seus impactos." (p.545). }\end{array}$ \\
\hline $\begin{array}{c}\text { Relação entre } \\
\text { Natureza e } \\
\text { Tecnologia } \\
\end{array}$ & $\begin{array}{l}\text { "fenômenos naturais e processos tecnológicos" (p.537, 539, 540, 543); "sistemas } \\
\text { naturais e tecnológicos" (p.541). }\end{array}$ \\
\hline
\end{tabular}

Fonte: autor, com base em BRASIL (2018)

O referencial teórico da área de Ciências Naturais da BNCC invoca três dessas tendências a partir da ênfase: de que, para o desenvolvimento científico dos estudantes é necessário o uso de diferentes tecnologias, entre elas as tecnologias digitais da informação e da comunicação (Desenvolvimento e aplicação de aparatos tecnológicos) (BRASIL, 2018, p. 537; 539); da importância de se interpretar os processos tecnológicos de modo que os estudantes paulatinamente tenham domínio dos conceitos e procedimentos importantes para entender a realidade (Aspectos Cognoscitivos) (BRASIL, 2018, p. 537), e da compreensão, não só das aplicações tecnológicas, como se é indicado nas etapas do ensino fundamental, mas, igualmente, de sua produção e de seu papel na sociedade (Enfoque CTS) (BRASIL, 2018, p. 539). 
Também encontramos essas três tendências de forma integrada, quando o documento sugere a possibilidade de habilidades argumentativas e de comunicação através do uso do instrumental tecnológico ancorados em princípios éticos, como pode ser verificado no seguinte excerto:

\begin{abstract}
Além disso, espera-se que eles aprendam a estruturar linguagens argumentativas que lhes permitam comunicar, para diversos públicos, em contextos variados e utilizando diferentes mídias e tecnologias digitais de informação e comunicação (TDIC), conhecimentos produzidos e propostas de intervenção pautadas em evidências, conhecimentos científicos e princípios éticos e responsáveis (BRASIL, 2018, p. 539).
\end{abstract}

Entre as competências específicas para o ensino médio, nota-se uma grande ênfase aos Aspectos Cognoscitivos necessários para o desenvolvimento de uma compreensão global da Tecnologia na sociedade, que poderíamos entender como Alfabetização Científico-Tecnológica. Entre os verbos utilizados para demarcar tais competências estão as ações de: analisar, realizar previsões, avaliar, interpretar, discutir, debater, explorar, compreender e utilizar noções (BRASIL, 2018, p. 539, 541, 544, 545).

É notável o entrelaçamento das diferentes tendências entre as competências específicas do ensino médio, por exemplo, a ação de analisar - ligada aos Aspectos Cognoscitivos - com a Relação entre Natureza e Tecnologia:

\begin{abstract}
Analisar fenômenos naturais e processos tecnológicos, com base nas relações entre matéria e energia, para propor ações individuais e coletivas que aperfeiçoem processos produtivos, minimizem impactos socioambientais e melhorem as condições de vida em âmbito local, regional e/ou global (BRASIL, 2018, p. 540, grifo nosso).
\end{abstract}

Os elementos centrais do Enfoque CTS também são visíveis na preocupação crítica do uso das tecnologias no mundo social e natural: "A compreensão desses processos é essencial para um debate fundamentado sobre os impactos da tecnologia nas relações humanas e suas implicações éticas, morais, políticas e econômicas, e sobre seus riscos e benefícios para a humanidade e o planeta" (BRASIL, 2018, p. 544).

Finalmente, tal como nas etapas de ensino anteriores, a área de Ciências Naturais do ensino médio, faz a articulação profunda entre Ciência e Tecnologia, quando explicita ambos os termos em mútua relação mediante os termos conhecimento científico $e$ tecnológico, avanço científico e tecnológico, e temas científicos e tecnológicos, o que indica que devem ser trabalhadas em conjunto. 


\section{Análise das tendências tecnológicas à luz da Perspectiva Reduzida e da Perspectiva Ampliada}

A partir da categorização das tendências tecnológicas realizada acima, é possível considerar que cada uma delas estão circunscritas nas metas curriculares de desenvolvimento da formação tecnocientífica dos estudantes brasileiros, seja por meio de dimensões teóricas, seja por meio de dimensões práticas. Entretanto, não fica evidente a profundidade em que cada uma dessas tendências são tratadas no que usualmente tem sido considerado como Alfabetização Científico-Tecnológica.

Ao analisar o processo de Alfabetização Científico-Tecnológica, Auler e Delizoicov (2001) apresentam duas possibilidades de compreendê-la no âmbito do ensino: pela Perspectiva Reducionista e pela Perspectiva Ampliada. A primeira referindose a uma abordagem de caráter mais ingênuo e acrítico e a segunda reconhecendo a criticidade como fundamento de elaboração, difusão e aquisição do conhecimento tecnológico e científico. Consideramos que uma comparação dessas duas perspectivas com as seis tendências classificadas no tópico 4 pode nos ajudar a responder se os conteúdos presentes nessas duas grandes diretrizes se baseiam em pautas críticas ou acríticas, o que implica no tipo de conhecimento científico-tecnológico que os estudantes irão receber para se alfabetizarem técnocientíficamente ${ }^{3}$.

Com base na tendência intitulada Aspectos Cognoscitivos, encontrada em ambos os documentos, podemos notar uma preocupação bastante clara de se incorporar uma visão da Tecnologia passível de ser problematizada, distanciada de uma perspectiva dogmática. Nos PCN+, grande parte dos verbos que definem as competências específicas da educação científica elucidam uma abordagem crítica do enfoque tecnológico de forma bastante clara, como no trecho: "Analisar, argumentar e posicionar-se criticamente em relação a temas de ciência e tecnologia" (BRASIL, 2002, p. 27; 37; 64; 90; 115, grifo nosso), além de ser uma tendência que se encontra integrada a outras preocupadas com os efeitos sociais e éticos da tecnologia, tais como o Enfoque CTS, como demonstra a passagem a seguir: "Reconhecer e avaliar o caráter ético do conhecimento científico e tecnológico e utilizar esses conhecimentos no exercício da cidadania” (BRASIL, 2002, p.32; 40; 68; 93; 118, grifo nosso).

\footnotetext{
3 As tendências foram dispostas em ordem alfabética para facilitar a compreensão do/a leitor/a, desconsiderando a ordem de frequência quantitativa de aparecimento.
} 
Na BNCC, verifica-se que a tendência Aspectos Cognoscitivos é bastante ampla e pragmática, com uma atenção particular, não só nas reflexões críticas das implicações tecnológicas no mundo, mas na divulgação pública dessas implicações, inclusive, pelo auxílio das novas tecnologias digitais:

\begin{abstract}
Analisar situações-problema e avaliar aplicações do conhecimento científico e tecnológico e suas implicações no mundo, utilizando procedimentos e linguagens próprios das Ciências da Natureza, para propor soluções que considerem demandas locais, regionais e/ou globais, e comunicar suas descobertas e conclusões a públicos variados, em diversos contextos e por meio de diferentes mídias e tecnologias digitais de informação e comunicação (TDIC)" (BRASIL, 2018, p. 544).
\end{abstract}

No que diz respeito à segunda tendência, a intensa Associação entre Ciência e Tecnologia em ambos os documentos implica em uma preocupação reflexiva direta com diferentes processos e fenômenos desses dois domínios, por exemplo, quando os PCN+ agregam a Ciência e a Tecnologia nos quadros de Contextualização Sociocultural de todas as áreas que compõem as Ciências Naturais, nos eixos: Ciência e tecnologia na história, Ciência e tecnologia na cultura contemporânea, Ciência e tecnologia na atualidade e Ciência e tecnologia, ética e cidadania (BRASIL, 2002, p. 32). Na BNCC, a postura problematizadora da Associação entre Ciência e Tecnologia, está ligada, especialmente, às referências feitas ao "conhecimento científico e tecnológico", quando destaca as ações cognitivas e reflexivas dos Aspectos Cognoscitivos, como demonstra o trecho a seguir: "analisar situações-problema e avaliar as aplicações do conhecimento científico e tecnológico nas diversas esferas da vida humana com ética e responsabilidade" (BRASIL, 2018, p. 544, grifo nosso).

Quanto à tendência Desenvolvimento e Aplicação dos aparatos tecnológicos verifica-se que esta encontra-se inserida em uma gama bastante ampla e complexa de relações que envolve, como já comentado, desde o desenvolvimento aos produtos e aplicação da Tecnologia (vide Quadro 1 e 2). Nos PCN+, encontra-se diretamente vinculado às competências gerais de ensino, integrado a outras tendências, como o Enfoque CTS, evidenciado no trecho a seguir: "Reconhecer e avaliar o desenvolvimento tecnológico contemporâneo, suas relações com as ciências, seu papel na vida humana, sua presença no mundo cotidiano e seus impactos na vida social” (BRASIL, 2002, p. 32; $40 ; 68 ; 93 ; 118)$. Na BNCC, embora nem todas as unidades de contextos dessa tendência estejam associadas à Perspectiva Ampliada, há indícios de uma preocupação crítica, ao citar o "uso criterioso de diversas tecnologias" (BRASIL, 2018, p. 537) e a importância do diálogo público por meio do uso de "diferentes mídias e tecnologias digitais de 
informação e comunicação" (BRASIL, 2018, p. 544), o que ilumina o aspecto democrático que a Ciência e a Tecnologia devem assumir.

A tendência Enfoque CTS é, talvez, a mais central em termos da Perspectiva Ampliada, pois como salientam Auler e Delizoicov (2001), as interações entre CiênciaTecnologia-Sociedade (CTS) são fundamentais para a "leitura do mundo" contemporâneo. No caso dos $\mathrm{PCN}+$, sua criticidade está dada ao se articular com os aspectos cognitivos que demandam a percepção pelos estudantes dos "efeitos positivos, mas também perturbadores, da ciência e da tecnologia na vida moderna" (BRASIL, 2002, p. 40), o reconhecimento da “[...] importância dos procedimentos éticos na aplicação das novas tecnologias [...]" (ibid., p. 40), e ainda o posicionamento "[...] no debate contemporâneo sobre as tecnologias de manipulações da vida" (ibid., p. 41). Todas essas passagens dão indicações de uma atitude problematizadora da Alfabetização CientíficoTecnológica, sob a orientação do Enfoque CTS, haja vista que uma das três metas principais deste tipo de alfabetização é exatamente a compreensão do impacto da Ciência e da Tecnologia sobre os indivíduos e a sociedade (LORENZETTI; DELIZOICOV, 2001).

Na BNCC encontramos trechos que consideramos harmônicos com a Perspectiva Ampliada do Enfoque CTS, quando sugerem aos estudantes a necessidade de entender e se debater "os impactos da tecnologia nas relações humanas, sejam elas locais ou globais, e suas implicações éticas, morais, culturais, sociais, políticas e econômicas, e sobre seus riscos e benefícios para o desenvolvimento sustentável e a preservação da vida no planeta" (BRASIL, 2018, p. 558). Esse caráter ampliado também pode ser verificado no interior das competências propostas, dentre elas a competência 3, que indica que os estudantes sejam capazes de "analisar situações-problema e avaliar as aplicações do conhecimento científico e tecnológico nas diversas esferas da vida humana com ética e responsabilidade" (BRASIL, 2018, p. 544).

A tendência História da Ciência e da Tecnologia também assume caráter crítico quando recorre aos processos históricos e sociais do homem na construção dos conhecimentos e artefatos tecnológicos e científicos. Entre os trechos que evidenciam a postura crítica nessa tendência, podemos citar, nos $\mathrm{PCN}+$, o trecho que afirma a importância de se "Compreender o conhecimento científico e o tecnológico como resultados de uma construção humana, inseridos em um processo histórico e social” (p. $32 ; 39 ; 67 ; 92 ; 117 ; 123)$. Curiosamente, não foi encontrado aspectos dessa tendência na área de Ciências da Natureza do ensino Médio na BNCC ao se considerar a abordagem 
histórica da ciência em conjunto com o enfoque tecnológico, embora o documento situe a cultura científica, em específico, como "uma das formas de organização do conhecimento produzido em diferentes contextos históricos e sociais, possibilitando-lhes apropriar-se dessas linguagens específicas" (BRASIL, 2018, p. 537).

A última tendência Natureza e Tecnologia, também não apresenta uma perspectiva reducionista, pois como menciona os $\mathrm{PCN}+$, se utilizando da disciplina Química como exemplo:

A proposta apresentada para o ensino de Química nos PCNEM se contrapõe à velha ênfase na memorização de informações, nomes, fórmulas e conhecimentos como fragmentos desligados da realidade dos alunos. Ao contrário disso, pretende que o aluno reconheça e compreenda, de forma integrada e significativa, as transformações químicas que ocorrem nos processos naturais e tecnológicos em diferentes contextos, encontrados na atmosfera, hidrosfera, litosfera e biosfera, e suas relações com os sistemas produtivo, industrial e agrícola (BRASIL, 2002, p. 87, grifo nosso).

Nessa tendência, a BNCC igualmente se prontifica a reconhecer os fenômenos naturais e os processos tecnológicos do ponto de vista da "avaliação de potencialidades e de limites e riscos do uso de diferentes materiais e/ou tecnologias para tomar decisões responsáveis e consistentes diante dos diversos desafios contemporâneos" (BRASIL, 2018, p. 540).

Em suma, as evidências acima asseguram que ambos os documentos procuram manter a Perspectiva Ampliada no tratamento dos conteúdos curriculares da área de Ciências Naturais do ensino médio, especialmente quando abordam questões com enfoque tecnológico. Sem dúvida, o distanciamento em relação à noções ingênuas e acríticas nessas duas diretrizes curriculares, próprias da Perspectiva Reducionista, pode ser explicada por já ter como base o novo paradigma surgido no final da década de 1970 que tornou pertinente a incorporação de uma abordagem interdisciplinar e transversal dos conteúdos e temas, contribuindo para uma imagem holística, crítica e mais realista do mundo.

\section{Considerações Finais}

Ao se analisar a área de Ciências Naturais de propostas curriculares nacionais do ensino médio, como os PCN+ e a BNCC, é possível a identificação de um conjunto de tendências tecnológicas que podem ser consideradas eixos fundamentais para o desenvolvimento do processo de Alfabetização Científico-Tecnológica dos estudantes brasileiros. No caso dos PCN+, seis tendências aparecem como centrais, diferindo quanto 
às suas abordagens temáticas, mas integradas de forma transversal, em muitos dos casos, são elas: 1. os Aspectos Cognoscitivos, preocupados com a compreensão instrumental do conhecimento tecnocientífico por parte dos estudantes, sendo a tendência que mais se aproxima de um dos três objetivos da Alfabetização Científico-Tecnológica, no quesito apreensão dos conceitos e desenvolvimento de competências e habilidades cognitivas; 2. a Associação entre Tecnologia e Ciência, cuja abordagem sincretiza os processos tecnológicos e científicos, visto possuírem íntima relação quanto aos seus meios e fins; 3. o Desenvolvimento e aplicação dos aparatos tecnológicos, com enfoques conceituais e utilitários, centrando-se no entendimento do desenvolvimento, produção e aplicação das tecnologias ao longo do tempo, além do próprio uso destas pelos estudantes em contexto de sala de aula; 4. o Enfoque CTS, com uma perspectiva contextual, social e axiológica que atravessa quase todas as demais tendências, por entender a Tecnologia de forma crítica, articulada com diferentes aspectos da realidade; 5. História da Ciência e da Tecnologia, ancorada em uma abordagem histórica da Tecnologia e da Ciência como produção e produto da ação prática dos homens em seu meio social; e, por fim, 6. Relação entre Natureza e Tecnologia, uma tendência que reconhece a relação intrínseca entre Natureza e Tecnologia, tanto no que tange ao processo cultural de hominização, quanto aos impactos das ações humanas, por meio da interferência da Tecnologia no meio ambiente. Na BNCC, é possível evidenciarmos a maioria das tendências supracitadas, com exceção da tendência História da Ciência e da Tecnologia, que não se manifesta nas unidades de contexto do enfoque tecnológico - embora esteja presente sob os aspectos históricos da Ciência.

A partir da constatação da presença de tais tendências nas propostas curriculares nacionais do ensino médio, é possível concluir que, de fato, há uma continuidade entre os enfoques tecnológicos presentes nos PCN e na BNCC do ensino fundamental e nos PCN+ e na BNCC do ensino médio, o que demonstra que são aspectos essenciais da temática tecnológica que devem ser trabalhados no contexto de ensino para o desenvolvimento da Alfabetização Científico-Tecnológica dos estudantes brasileiros.

Ademais, a consideração de cada tendência sob o viés da Perspectiva Reducionista e da Perspectiva Ampliada da Alfabetização Científico-Tecnológica, tal como formuladas por Auler e Delizoicov (2001) demonstrou que todas elas se enquadram nesta última, exatamente porque consideram o enfoque tecnológico mediante uma visão crítica e problematizadora e se colocam contrárias à imagem fragmentada das relações entre 
Ciência, Tecnologia, Sociedade e Meio-Ambiente, própria das concepções ingênuas de educação científica.

\section{Referências}

AMARAL, I. A. do. Currículo de Ciências: das tendências clássicas aos movimentos atuais de renovação. In: BARRETO, E. S.S. (org.). Os currículos do ensino fundamental para as escolas brasileiras. Campinas: Autores Associados, São Paulo: Fundação Carlos Chagas, 1998. (Coleção formação de professores). p. 201-232.

AULER, D. Alfabetização científico-tecnológica: um novo "paradigma"?. Ensaio Pesquisa em Educação em Ciências, Belo Horizonte, v. 5, n. 1, p. 68-83, mar., 2003. Disponível em: https://www.scielo.br/pdf/epec/v5n1/1983-2117-epec-5-01-00068.pdf. Acesso em: 20 jan. 2021.

AULER, D.; DELIZOICOV, D. Alfabetização científico-tecnológica para quê?. Ensaio Pesquisa em Educação em Ciências, Belo Horizonte, v. 3, n. 2, p. 122-134, jul./dez., 2001. Disponível em: https://www.scielo.br/scielo.php?pid=S198321172003000100068\&script=sci_arttext\&tlng=pt. Acesso em: 20 jan. 2021.

BARDIN, L. Análise de conteúdo. São Paulo: Edições 70, 2002.

BRASIL. Parâmetros Curriculares Nacionais - Ciências Naturais. Brasília: MEC, 1997. Disponível em: http://portal.mec.gov.br/seb/arquivos/pdf/livro04.pdf. Acesso em: 14 abr. 2021.

BRASIL. Parâmetros Curriculares Nacionais - Ciências Naturais. Brasília: MEC, 1998. Disponível em: http://portal.mec.gov.br/seb/arquivos/pdf/ciencias.pdf. Acesso em: 14 abr. 2021.

BRASIL. PCN+ Ensino Médio: Orientações Educacionais Complementares aos Parâmetros Curriculares Nacionais. Ciências da Natureza, Matemática e suas Tecnologias. Brasília: MEC, SEMTEC, 2002. Disponível em: http://portal.mec.gov.br/seb/arquivos/pdf/CienciasNatureza.pdf. Acesso em: 20 jan. 2021.

BRASIL. Ministério da Educação. Base nacional comum curricular. Brasília, DF: MEC, 2018. Disponível em:

http://portal.mec.gov.br/index.php?option=com_docman\&view=download\&alias=85121-bnccensino-medio\&category_slug=abril-2018-pdf\&Itemid=30192. Acesso em: 20 jan. 2021.

CACHAPUZ, A. F. Epistemologia e Ensino das Ciências no Pós-Mudança Conceptual: Análise de um Percurso de Pesquisa. In: II Encontro Nacional de Pesquisa em Educação em Ciências, 2, 1999, Valinhos. Atas do II ENPEC... Valinhos, 1999. p. 01-10.

KRASILCHIK, M. Caminhos do ensino de ciências no Brasil. Em Aberto, Brasília, v. 11, n. 55, p. 3-8, jul./set., 1992. Disponível em:

http://rbep.inep.gov.br/ojs3/index.php/emaberto/article/view/2153. Acesso em: 10 jan. 2021.

KRASILCHIK, M. Reformas e realidade: o caso do ensino das ciências. São Paulo em perspectiva, São Paulo, v. 14, n. 1, p. 85-93, jan./mar., 2000. Disponível em: https://www.scielo.br/pdf/spp/v14n1/9805.pdf. Acesso em: 10 jan. 2021.

LORENZETTI, L.; DELIZOICOV, D. Alfabetização científica no contexto das séries iniciais. Ensaio Pesquisa em educação em Ciências, Belo Horizonte, v. 3, n. 1, p. 37-50, 
jan./jun., 2001. Disponível em: https://www.scielo.br/pdf/epec/v3n1/1983-2117-epec-3-0100045. Acesso em: 25 jan. 2021.

SANTOS, W. R. A frequência e as tendências do enfoque tecnológico na área de Ciências Naturais: uma análise a partir dos Parâmetros Curriculares Nacionais e da Base Nacional Comum Curricular. In: Educação e Inovação: práticas educacionais inovadoras com uso das tecnologias. Goiânia: Editora IF Goiano. No prelo. 2021.

Recebido em: 30 de janeiro de 2021.

Aceito em: 12 de abril de 2021. 